\title{
Oxygen Transfer Mechanisms in the Gluconic Acid Fermentation by Pseudomonas Ovalis
}

\author{
GARY F. BENNETT* and LLOYD L. KEMPE, Department of \\ Chemical and Metallurgical Engineering, The University of Michigan, \\ Ann Arbor
}

\begin{abstract}
Summary
The oxygen uptake rate to suspended cells of Pseudomonas ovalis was measured in two ways using the same cell suspension. Initially the rate was found by measuring the rate of production of gluconic acid by cells suspended in a nitrogenfree, aerated medium. Then, an oxygen electrode was used to measure the rate of transfer of dissolved oxygen to cells suspended in a liquid that was being agitated but not sparged. These rates were markedly different. It was found that agitation affected the oxygen transfer rates in aerated solutions at dissolved oxygen concentrations well above the critical level, but had no affect on the oxygen uptake rates by cells suspended in an unsparged but agitated medium. The data suggested that an additional path existed for oxygen transfer. This alternate route, parallel to the conventional pathway of oxygen transfer, becomes operative when the liquid films surrounding the cells and bubbles merge. The resulting shorter path presents a mechanism for direct transfer of oxygen which increases in importance as the gas-liquid interfacial area increases.
\end{abstract}

\section{INTRODUCTION}

Submerged aerobic fermentations are used industrially to produce antibiotics, chemicals, yeast cells, and vitamins, and are also used in waste treatment. These fermentations require that large amounts of oxygen be supplied to microorganisms submerged in liquids in order to support growth of the cultures.

The microorganisms must be continually supplied with essential nutrients at rates sufficiently high to prevent limitation of their metabolic activities. At the same time, metabolic products must be continually renoved to prevent inhibition of growth processes of the cells.

* Present address: Department of Chemical Engineering, The University of Toledo, Toledo, Ohio. 
In aerobic fermentations, oxygen becomes an essential nutrient. Not only does it have a long, difficult path to travel from air to reaction sites in the cell, but it also has a very low solubility in the medium. (Fig. 1).

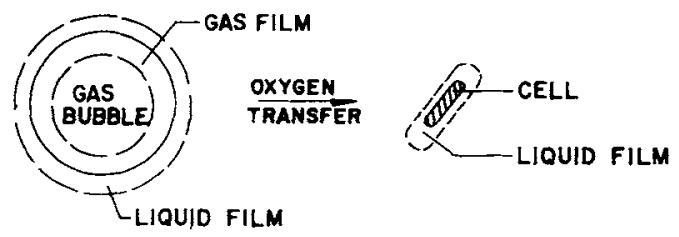

Fig. 1. Path of oxygen transfer in submerged aerobic fermentations.

Oxygen is transferred in a series of steps, each stage having its own resistance. The relative importance of each of these resistances depends upon the system. The first three resistances, those of the gas film, the interface, and the liquid film, are connected with the air bubbles. They are usually combined into a single resistance with that of the liquid film being considered the most important.

There is a liquid film surrounding the cells which could also be significant. In the production of gluconic acid by suspended cells of Pseudomonas ovalis, Tsao and Kempe ${ }^{1}$ proposed that the ratelimiting step for oxygen transfer occurred at the cell-liquid interface. Finn, ${ }^{2}$ however, has calculated that this resistance is small and not significant.

Tsao and Kempe felt that agitation reduced the thickness of the film resulting in increased oxygen transfer rates (OTR). Finn ${ }^{3}$ disputed this view. He stated that agitation in excess of that required to uniformly suspend individual cells would not markedly improve oxygen transfer from the liquid to the cell wall, because the cells move with the liquid. According to this view, improvement in oxygen transfer rates through this film could only be achieved by increasing the relative movements between cells and the liquid. Blakebrough and Hamer ${ }^{4}$ concurred, finding that agitation intensity had no effect on the liquid-cell interfacial resistance.

In work with the novobiocin fermentation, Maxon and Steel ${ }^{5}$ increased the OTR by agitating the liquid more vigorously. This increased OTR occurred even though the dissolved oxygen concentration was well above the critical level throughout their experiments. 
They concluded that the cell-liquid resistance becomes the controlling factor for oxygen transfer in viscous, non-newtonian fermentations like the novobiocin fermentation. They did not indicate that this applied to low viscosity broths, asserting that the gasliquid film still controlled in this instance.

\section{MATERIALS AND METHODS}

The culture of Pseudomonas ovalis NRRL B-8 used in this study was obtained from the Northern Utilization Research and Development Division of the United States Department of Agriculture at Peoria, Illinois. This microorganism elaborates gluconic acid when suspended in a glucose medium that is aerated. The overall reaction is:

$$
\begin{array}{ll}
\mathrm{C}_{6} \mathrm{H}_{12} \mathrm{O}_{6}+1 / 2 \mathrm{O}_{2} & \rightarrow \mathrm{C}_{6} \mathrm{H}_{12} \mathrm{O}_{7} \\
\text { glucose } & \text { gluconic acid }
\end{array}
$$

Tsao and Kempe ${ }^{1}$ reported, and the present study confirmed, that in a resting cell suspension $99 \%$ of the glucose fermented is converted into gluconic acid by this organism.

\section{Equipment}

The details of the construction of the fermentor and the $\mathrm{pH}$ controlling equipment have been previously described. ${ }^{1}$ The fermentor was of conventional design (New Brunswick Scientific Company, New Brunswick, N.J., Model F-05) composed of a 5 l. glass jar, two sets of four bladed impellers, and four vertical baffles. A calomel and a glass electrode system were inmersed in the fermenting liquid to measure the $\mathrm{pH}$. The electrodes were connected to a $\mathrm{pH}$ recorder-controller. Since the cells elaborated gluconic acid during the experiment, the $\mathrm{pH}$ always decreased. When the $\mathrm{pH}$ reached a set value, the controller started a peristaltic-action finger pump (Sigmamotor, Inc., Middleport, New York). Sodium hydroxide was pumped from a buret, through a small tube, to the fermentor. The rate in base addition was proportional to the rate of acid production and hence to the rate of oxygen utilization.

\section{Experimental Procedure}

The culture was maintained on agar slants, at $30^{\circ} \mathrm{C}$; ; daily transferals were made. To prepare for an experiment, cells were washed 
from the agar surface of a $24 \mathrm{hr}$. slant culture with $10 \mathrm{ml}$. of fresh, sterile, liquid medium. The suspension was then poured into a $2 \mathrm{l}$. Erlenmeyer flask containing $1.1 \mathrm{l}$. of sterile media. This culture was shaken for $24 \mathrm{hr}$. at $30^{\circ} \mathrm{C}$. The cells were centrifuged from the broth of $250 \mathrm{ml}$. bottles at 2000 r.p.m. using an International, Clinical Centrifuge, size No. 2. The cells were then resuspended in $2 \mathrm{l}$. of a solution of the following composition:

\begin{tabular}{ll} 
Glucose & $50 \mathrm{~g}$. \\
$\mathrm{KH}_{2} \mathrm{PO}_{4}$ & $0.9 \mathrm{~g}$. \\
$\mathrm{K}_{2} \mathrm{HPO}_{4}$ & $0.6 \mathrm{~g}$. \\
Distilled water & $2.0 \mathrm{l}$. \\
Polyglycol, P-200 & 0.025 ml. (Dow Chemical Co., \\
& \multicolumn{2}{c}{ Midland, Michigan) } \\
pH & 7.0
\end{tabular}

This solution contained no nitrogen. The cell suspension was adjusted to a standard optical density and placed in the fermentor. The air flow, agitator, and $\mathrm{pH}$ controller were started and the $\mathrm{pH}$ controlled at 7.0 \pm 0.1 . Air was passed through the sparger into the medium at the rate of 1 VVM. The level of the sodium hydroxide in the buret was recorded every $5 \mathrm{~min}$. This level fell slowly at first, but increased and attained a steady rate in about one hour. The rate of sodium hydroxide addition was proportional to the rate of gluconic acid production.

The oxygen electrode (Beckman Instruments, Fullerton, California, No. 11098) was not installed until the rate of gluconic acid production reached a constant level. Before being used to measure the rate of oxygen utilization, the electrode was standardized in a glucosephosphate solution that was saturated with air at the same temperature as the liquid in the fermentor $\left(25.0^{\circ} \mathrm{C}\right.$.). The electrode was adjusted to read $100 \%$ saturation. Then, the electrode was placed in the liquid medium in the fermentor.

The air flow and agitation were resumed. When the dissolved oxygen concentration in the mediun reached a steady value, the air flow was stopped; the agitator was not. The dissolved oxygen concentration then began to fall and its value was recorded as a function of time. 


\section{RESULTS}

Even though the introduction of air to the fermentor was stopped, the microorganisms continued to utilize dissolved oxygen (DO) at a rate independent of the DO concentration as predicted by the conventional theory of the critical oxygen concentration. This is shown

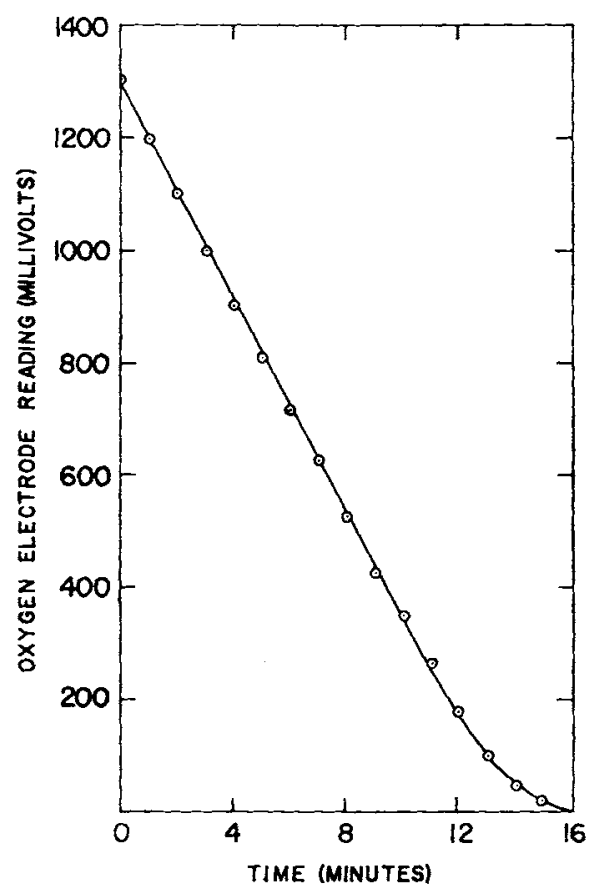

Fig. 2. Measurement of the rate of oxygen utilization by resting cells of Pseudomonas ovalis using the oxygen probe with agitation at 114 r.p.m. and no aeration.

in Figure 2. The value at which the rate of oxygen utilization became dependent on DO is defined as the critical DO concentration. The determination of the critical oxygen concentration is illustrated in Figure 3 where the rate of oxygen utilization is plotted as a function of the DO concentration. The gluconic acid production method was used to measure the OTR only in fermentations where air was sparged into the medium: the oxygen electrode was used to determine the OTR in agitated, but unsparged broths. To employ 
oxygen electrode measurements for calculating the OTR, the decay of DO with time was observed and the following formula employed:

$$
(\mathrm{OTR})_{E}=\frac{(d E / d t) C^{*}}{(1 / 60 \times 32)\left(E_{s}-E_{0}\right)} \cdot \frac{\text { mmoles oxygen }}{1 .-\mathrm{hr} .}
$$

In this expression, $d \mathrm{E} / d \mathrm{t}$ is the slope of the plot of the electrode readings against time (Fig. 2$) ;\left(E_{s}-E_{o}\right)$ is the difference between the

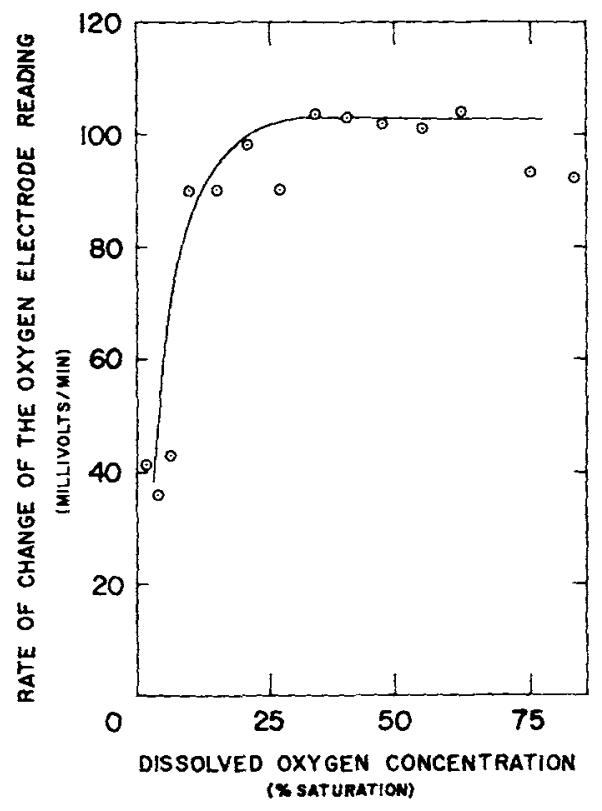

Fig. 3. Effect of dissolved oxygen concentration on the rate of oxygen utilization by resting cells of $P$ seudomonas ovalis with no aeration at pH 7.0 and $25^{\circ} \mathrm{C}$.

electrode readings taken in a glucose-phosphate buffer solution when the liquid was saturated with oxygen from the air, and readings taken in a solution completely devoid of oxygen.

The saturation concentration of DO in distilled water, contacting air at atmospheric pressure $C^{*}$, has been reported to be $8.18 \mathrm{mg}$./l. at $25.0^{\circ} \mathrm{C}{ }^{6}$ The medium used to suspend the cells contained glucose, sodium-mono- and sodium-di-hydrogen phosphate, sodium gluconate, and an antifoaming agent. The amount of oxygen needed to satuBIOTECHNOLOGY AND BIOENGINEERING, VOL. VI, ISSUE 3 


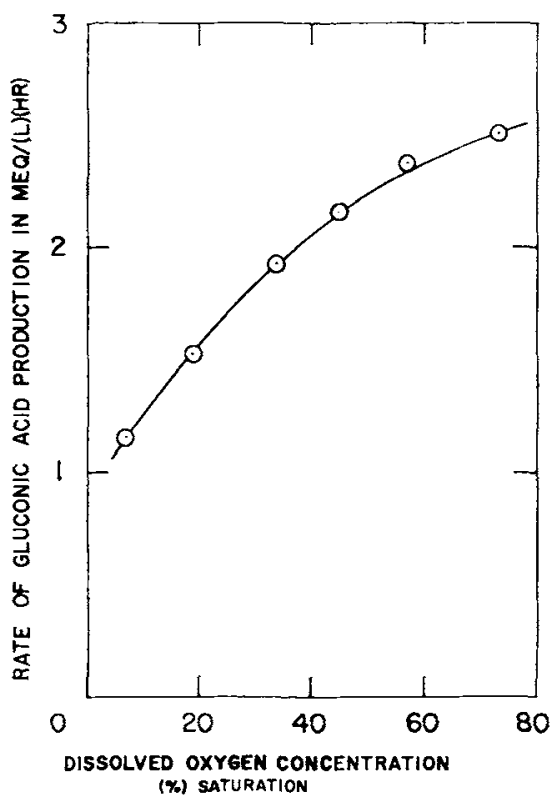

Fig. 4. Effect of oxygen concentration on the rate of gluconic acid production (speed and air flow rate varied) by resting cells of Pseudomonas ovalis at $\mathrm{pH} 7.0$ and at $25^{\circ} \mathrm{C}$.

rate the solution was calculated to be $6.8 \mathrm{mg}$./l., using data from Solomons. ${ }^{7}$

It was found ${ }^{8}$ that the rate of gluconic acid production increased when either the stirring speed or the air flow rate was increased, (Fig. 4). This confirmed earlier data taken by Tsao. ${ }^{9}$ In addition, measurements taken with the oxygen electrode showed that the DO concentrations were high in the liquid when these increases occurred.

In another run (Fig. 5), the agitator speed was 300 r.p.m. and the air flow rate 1.0 VVM, while the concentration and the rate of gluconic acid production increased, even though the DO concentration was well above the critical value of approximately $17 \%$ saturation. A parallel run was made at an agitator speed of 400 r.p.m. with similar results, except that the gluconic acid production rate was higher than at 300 r.p.m. 


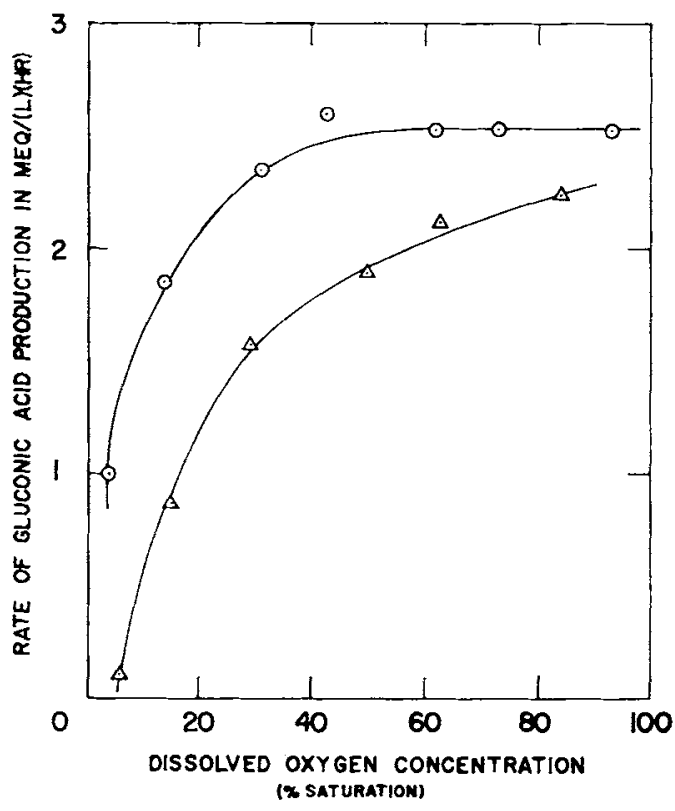

Fig. 5. Effect of oxygen concentration on the rate of gluconic acid production by resting cells of Pseudomonas ovalis at $25^{\circ} \mathrm{C}$, a constant air rate of $1.00 \mathrm{VVM}$ and a $\mathrm{pH}$ of $7.0 . \odot, 400$ r.p.m.; $\triangle, 300$ r.p.m.

Measurement of the OTR using the gluconic acid production method in a system indicated a definite dependence of OTR on the stirring speed. However, when the OTR was measured with the oxygen electrode in an unsparged system the OTR was found to be independent of the stirring speed; more importantly, the OTR measured with the electrode in an unsparged system was approximately one half of that found in the sparged system.

\section{DISCUSSION}

Oxygen is an essential nutrient for aerobic microorganisms being grown while submerged in fermentation mashes. Since oxygen is a rather insoluble gas, microorganisms suspended in an aqueous solution find only a small supply of dissolved oxygen available. This supply must be continually renewed by aeration and agitation of the medium. 
Conventionally, it is thought that the microorganisms utilize only dissolved oxygen. Indeed, this is the basis upon which the concept of a critical oxygen concentration depends. However, the source of dissolved oxygen for microbial growth during submerged fermentations, is the air emitted from the sparger. Oxygen is transferred from the air bubbles to the cells in a series of steps; each step has its own resistance in the transfer process. The total resistance to oxygen transfer in bacterial fermentations is the sum of the following individual resistances:

$R_{1}$ the resistance of the gas film at the air-liquid interface.

$R_{2}$, the resistance of the liquid film at the air-liquid interface.

$R_{3}$, the resistance of the bulk liquid.

$R_{4}$, the resistance of the liquid film surrounding the cell.

According to present concepts, the rate of oxygen uptake by the cells is independent of the dissolved oxygen concentration as long as the latter remains above the critical value $\left(C_{c}\right)$. According to Finn, ${ }^{2}$ this value is low for unicellular organisms. Several examples of $C_{c}$ values are listed in Table I.

It is important to note that another, concurrent route for oxygen transfer was outlined long ago by Bartholomew et al. ${ }^{14}$ They suggested that a parallel, but shorter path for oxygen transfer occurred when the cells were adsorbed on to the bubbles.

\section{TABLE I}

Critical Dissolved Oxygen Concentrations for

Microorganisms in the Presence of Substrate

\begin{tabular}{lcc}
\hline \multicolumn{1}{c}{ Organism } & $\begin{array}{c}\text { Critical } \\
\text { dissolved oxygen } \\
\text { concentrations, mg./l. }\end{array}$ & Ref. \\
\hline $\begin{array}{l}\text { Luminous bacteria } \\
\text { Azotobacter }\end{array} \quad 0.31$ & 2 \\
$\quad$ Vinelandii & $0.56-1.53$ & 2 \\
Yeast & $0.10-0.11$ & 2 \\
Yeast & 0.25 & 10 \\
Penicillium & & \\
$\quad$ chrysogenum & 0.66 & 2 \\
Escherichia coli & 0.26 & 2 \\
Saccharomyces & & 11 \\
$\quad$ cerevisiae & 0.20 & 12 \\
Pseudomonas sp. & 0.2 & 13 \\
Pseudomonas ovalis & 0.7 & \\
\hline
\end{tabular}




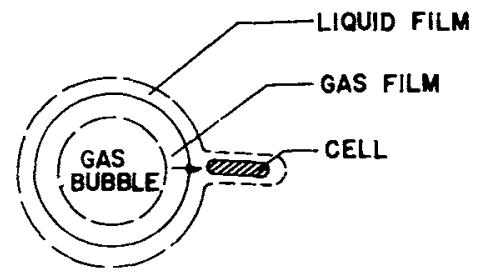

Fig. 6. Path of oxygen transfer with micro-organisms absorbed on the surface of a bubble.

Such a system is illustrated in Figure 6. When cells are adsorbed onto the surface of bubbles, the liquid films surrounding the cell and the bubble can merge. Resistances $R_{2}$ and $R_{4}$ could thus become a single resistance, and $R_{3}$ and the resistance to diffusion of the bulk of the liquid would be eliminated. A direct, shorter path for oxygen transfer would thus be available by which oxygen could diffuse from air bubbles into the common liquid film and then pass directly to the cell.

Bartholomew et al. ${ }^{14}$ were unable to support their model with adequate experimental evidence due to the limitations of equipment available at that time. They had indirect evidence, however, which suggested that a direct means of oxygen transfer did exist.

The concentration of solids at interfacial boundaries is a well known phenomenon. For example, froth flotation has long been used to concentrate metallic ores and to separate useful minerals from worthless rock. ${ }^{15}$ Air bubbles adhere to mineral particles in water and bring them to the surface as a froth. It is also well known that microorganisms adhere to bubbles. Gaudin et al. ${ }^{16}$ have presented data for the froth flotation of Escherichia coli. Many other organisms have been concentrated by froth flotation. ${ }^{17-19}$ Our own experiments with Pseudomonas ovalis indicate about a $20 \%$ increase of cell concentration in the froth when the cells were suspended in a nitrogen-free medium of glucose and sodium phosphate and then were sparged with air.

The results presented in this paper indicate that this direct path for oxygen transfer occurs in submerged aerobic fermentations. Figure 4 shows that the OTR increased with each increase of the air flow rate or of the stirring speed: this occurred even though the dissolved oxygen concentration in the liquid was well above the 
critical. Similar results were reported by Tsao and Kempe ${ }^{1}$ but they attributed the effect to a decrease in the resistance to oxygen transfer at the cell-liquid interface as a result of increased turbulence. Steel and Maxon ${ }^{20}$ found a similar increase in the OTR during the novobiocin fermentation as the agitation rate was increased. They too had dissolved oxygen concentrations above the critical level when this effect was noted.

The surface area available for adsorption of bacterial cells is directly related to the area of the gas-liquid interface. Blakebrough and Hamer ${ }^{4}$ added fibers to bacterial suspensions and found a reduction in the OTR; they attributed this reduction to some organisms becoming attached to the suspended fibers, thereby reducing the area available for mass transfer. Bartholomew and co-workers ${ }^{14}$ noted that this area was important by stating that direct oxygen transfer would be favored "by a large number of small bubbles having a large interfacial area, coupled with thorough mixing between bubbles and cells."

$\mathrm{Tsao}^{9}$ has reported values indicating the magnitude of the increase in the volume of air retained in the fermenting medium as the speed and stirring rate were increased. Data taken in the present study verified Tsao's results. As the oxygen concentration in the air was arbitrarily lowered, the OTR was found to fall (Fig. 5) even though the DO concentration in the liquid was still well above the critical value. Reducing the oxygen content of the gas reduced the available driving force for oxygen transfer by the direct process. The film joining the cell and the bubble acts as a membrane; according to Strohm and Dale ${ }^{21}$ this film functions similarly to the membrane in the membrane-covered electrode, used in this work for measurement of oxygen activity in the liquid. The conclusion drawn from this analogy is that oxygen activity in the solution, or the partial pressure of oxygen in the gas is a more important parameter for controlling oxygen transfer than is the DO concentration in the liquid. For DO measurements, the response of the electrode is proportional to the partial pressure of oxygen; similarly for bacterial respiration, the OTR is affected by the partial pressure of oxygen in the gas phase.

Measurements taken with the oxygen electrode in an unaerated system showed no affect of stirring speed on the OTR. This finding agrees with that of Blakebrough and Hamer. ${ }^{4}$ Thus the liquid film surrounding the cell is not the site of the controlling resistance for 


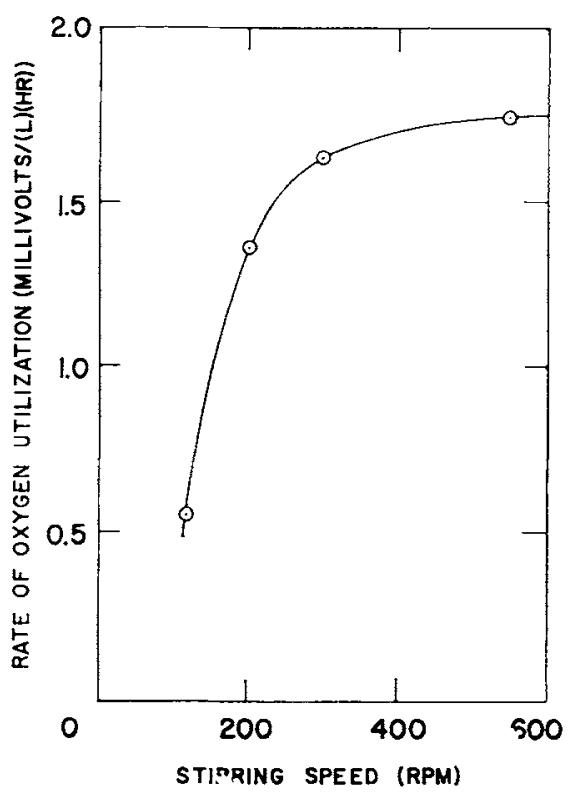

Fig. 7. Effect of agitation speed on the rate of oxygen utilization by resting cells of Pseudomonas ovalis.

oxygen transfer. On the other hand, in the aerated liquid an increase in speed from 300 to 400 r.p.m. increased the oxygen uptake of the cells at each dissolved oxygen concentration. We attribute this effect to an increase in the gas-liquid interfacial area.

As shown in Figure 7, when the system was being aerated the OTR increased as a function of the stirring speed. However, when aeration was stopped the oxygen utilization rate dropped immediately; the new rate of oxygen transfer in the unaerated system was about one half of the maximum rate when the liquid was being aerated and agitated. The difference between the two rates represents the effect of aeration on oxygen transfer: as the agitation rate was increased, the difference increased. This was expected, since the surface area available for bacterial adsorption increased as the gas retention increased and gas retention is a function of the air flow rate.

Siegell and Gaden ${ }^{22}$ reported a similar finding in a study of yeast respiration in a sparged and unsparged system. They attributed BIOTECHNOLOGY AND BIOENGINEERING, VOL. VI, ISSUE 3 
this difference in oxygen transfer rate "to the change from an environment of active aeration and agitation in the fermentor to the static conditions of the sample chamber" in a polarographic cell.

Phillips et al. ${ }^{23}$ have also expressed dissatisfaction with the accepted theories and mechanisms that describe the effects of liquid behavior on the OTR in fermentations. They too decided that no single mechanism could explain their data. They proposed that oxygen transfer was a result of normal diffusional processes together with the incorporation into the medium of oxygen molecules adsorbed on the surface of the liquid.

The mechanism of direct oxygen transfer presented in the present paper proposes an independent, additive path for the transfer of oxygen to cells adsorbed on the bubble. This path utilizes a liquid film common to the cell and air bubble.

\section{CONCLUSION}

The OTR in an unsparged, but agitated system is less than the OTR in a system that is both sparged and agitated at the same time. The differences between these measurements increase as the gasliquid interface or the partial pressure of oxygen in the gas is increased.

These data suggest that two parallel paths exist for the transfer of oxygen from air to the cell. In the unsparged liquid, the cell has available only oxygen dissolved in the liquid; in this case only one path is operative. In sparged media, another path becomes important. Some of the cells adsorb onto air bubbles, or air bubbles adsorb onto cells, with a consequent merging of the liquid films; this intimate contact provides a path for direct transfer of oxygen from the bubbles so adsorbed, thereby circumventing diffusional resistance of the bulk of the liquid and of one of the liquid films. By this process, some of the resistance to oxygen transfer is reduced for some of the cells and increased oxygen transfer is promoted even when the DO concentration in the liquid is well above the critical value.

This study was aided by National Science Foundation Grant No. GP-1007.

\section{References}

1. Tsao, G. T. N., and L. L. Kempe, J. Biochem. Microbiol. Technol. Eng., 2, $129(1960)$.

2. Finn, R. K., Bacteriol. Rev., 18, 254 (1954). 
3. Finn, R. K., paper presented at 136th Meeting, American Chemical Society, Atlantic City, New Jersey, Sept., 1959.

4. Blakebrough, N., and G. T. Hamer, Biotech. Bioeng., 5, 59 (1963).

5. Steel, R., and W. D. Maxon, paper presented at 139th Meeting, American Chemical Society, Atlantic City, New Jersey, Sept., 1962.

6. Committee on Sanitary Eng. Rsch. of the Sanitary Eng. Div., J. Sanit. Eng. Div. Am. Soc. Civil Engrs., 86, 2556 SA4 (1960).

7. Solomons, G. L., Soc. Chem. Ind, London, Monograph, 12, 233 (1961).

8. Bennett, Gary F., Ph.D. Thesis, The University of Michigan, Ann Arbor, 1963.

9. Tsao, G. T. N., Ph.D. Thesis, The University of Michigan, Ann Arbor, 1959 .

10. Rolinson, G. N., J. Gen. Microbiol., 6, 336 (1952).

11. Strohm, J. A., R. R. Dale, and H. J. Peppler, Appl. Microbiol., 7, 235 (1959).

12. Sultzer, B. M., J. Bacteriol., 82, 492 (1961).

13. Aiba, S., M. Hara, and J. Someya, Progress Report No. 21, Biochem. Eng. Lab., Inst. Appl. Microbiol., Univ. of Tokyo, Japan, 1962.

14. Bartholomew, W. H., E. O. Karow, M. R. Sfat, and R. H. Wilhelm, Ind. Eng. Chem., 42, 1801 (1953).

15. Gaudin, A. M., Flotation, 2nd ed., McGraw-Hill, New York, 1957.

16. Gaudin, A. M., N. S. Davis, and S. E. Bangs, Biotech. Bioeng., 4, 211 (1962).

17. Black, S. H., R. E. MacDonald, T. Hashimoto, and P. Gerhardt, Nature, $185,782(1960)$.

18. Gaudin, A. M., A. L. Mular, and R. F. O'Comnor, Appl. Microbiol., 8, $84(1960)$.

19. Gaudin, A. M., A. L. Mular, and R. F. O'Connor, Appl. Microbiol., 8, 91 (1960).

20. Steel, R., and W. D. Maxon, Biotech. Bioeng., 4, 231 (1962).

21. Strohm, J. A., and R. F. Dale, Ind. Eng. Chem., 53, 760 (1961).

22. Siegell, S. D., and E. L. Gaden, Jr., Biotech. Bioeng., 4, 345 (1962).

23. Phillips, K. L., H. R. Sallans, and J. F. T. Spencer, Ind. Eng. Chem., 57, 749 (1961).

Received May 11, 1964 